\title{
Variáveis ruminais em novilhos alimentados com feno de Tifton 85 com diferentes tamanhos de partículas
}

\author{
Ruminal variables in steers fed with Tifton 85 (Cynodon Spp) hay \\ with different particle sizes
}

\author{
Elzânia Sales Pereira ${ }^{1 *}$; Ivone Yurika Mizubuti²; Arturo Bernardo Selaive \\ Villarroel $^{3}$; Sônia Maria Pinheiro de Oliveira ${ }^{3}$; Patrícia Guimarães Pimentel ${ }^{4}$
}

\section{Resumo}

\begin{abstract}
As concentrações de nitrogênio amoniacal $\left(\mathrm{N}^{-\mathrm{NH}_{3}}\right)$ e $\mathrm{pH}$ foram determinadas objetivando avaliar o efeito de diferentes tamanhos de partículas de feno de Tifton $85(5,7,10 \mathrm{~mm}$ e inteiro) na dieta de novilhos holandeses, castrados, com peso vivo médio de $300 \mathrm{~kg}$ e idade média de 20 meses. As determinações das concentrações de amônia ruminal $\left(\mathrm{N}^{-\mathrm{NH}_{3}}\right)$ e o $\mathrm{pH}$ foram analisadas em delineamento inteiramente casualizado, em esquema de parcela subdivididas, tendo nas parcelas os tratamentos experimentais (5, $7,10 \mathrm{~mm}$ e feno inteiro) e nas sub-parcelas os tempos de coleta $(0,2,4,6,8 \mathrm{~h})$, com quatro repetições. A utilização de dietas constituídas com tamanhos de $5 \mathrm{~mm}$ e partícula inteira não afetaram o $\mathrm{pH}$ ruminal ( $\mathrm{P}>0,05)$, registrando-se valores médios de pH 6,14 e 6,61, respectivamente. Verificou-se redução linear no $\mathrm{pH}$ ruminal dos novilhos alimentados com a dieta constituída com partícula de $10 \mathrm{~mm}$ e constatou-se efeito quadrático para a dieta constituída com tamanho de partícula de feno de Tifton $7 \mathrm{~mm}$, apresentando pH mínimo de 5,39 a 8:00 horas após o fornecimento da alimentação. As concentrações de $\mathrm{N}-\mathrm{NH}_{3}$ foram influenciadas quadraticamente pelos tempos de coleta, registrando concentrações máximas, de 15,$55 ; 15,83 ; 18,32 ; 12,00 \mathrm{mg} / 100 \mathrm{~mL}$ de $\mathrm{N}_{-} \mathrm{NH}_{3}$ às $4: 28 ; 3: 58 ; 2: 99$ e 2:80 horas após alimentação, para as dietas constituídas de feno de Tifton 85 inteiro, picado em $5 \mathrm{~mm}, 7 \mathrm{~mm}$ e $10 \mathrm{~mm}$, respectivamente. Concluiu-se que todas as dietas permitiram padrões nictemerais normais de fermentação.

Palavras-chave: Fermentação, nitrogênio amoniacal, $\mathrm{PH}$, ruminantes
\end{abstract}

\begin{abstract}
The ammonia nitrogen $\left(\mathrm{N}-\mathrm{NH}_{3}\right)$ concentration and the $\mathrm{pH}$ were determined with the objective of evaluating the effect of different particle sizes $(5,7,10 \mathrm{~mm}$ and whole) of Tifton 85 hay in the diet of Holstein steers, with average live weight of $300 \mathrm{~kg}$ and age of 20 months. A completely randomized design, with four replicates, in a split-plot arrangement was used. The plots were the experimental treatments $(5,7,10 \mathrm{~mm}$ and whole hay) and the subplots were the times of collection $(0,2,4,6,8 \mathrm{~h})$. The use of diets including hay with particle sizes of $5 \mathrm{~mm}$ and whole, did not affect $(\mathrm{P}>0,05)$ the ruminal $\mathrm{pH}$; average values were 6.14 and 6.61, respectively. A linear reduction in the ruminal $\mathrm{pH}$ was verified in the steers fed on diets constituted by $10 \mathrm{~mm}$ particles. For the diets including Tifton hay with particle
\end{abstract}

1 Professor da Universidade Federal do Ceará, Departamento de Zootecnia. Av Mister Hull S/N. Fortaleza, CE, Brasil. CEP 60.021970. Telefone: (85) 3366 9695. Autor para correspondência. Email: elzania@hotmail.com

2 Professor da Universidade Estadual de Londrina, Departamento de Zootecnia, Londrina, PR, Brasil. Bolsista Produtividade do CNPq.

3 Professor da Universidade Federal do Ceará, Departamento de Zootecnia. Av Mister Hull S/N. Fortaleza, CE, Brasil. CEP 60.021970.

4 Pesquisadora da Universidade Federal do Ceará (UFC), Departamento de Zootecnia, Fortaleza, CE, Brasil. Bolsista do Programa de DCR, FUNCAP/CNPq.

* Autor para correspondência 
size of $7 \mathrm{~mm}$, it was observed a quadratic effect, where the minimum $\mathrm{pH}$ (5.39) was observed 8:00 $\mathrm{h}$ after the feed was furnished. Concentrations of $\mathrm{N}^{-\mathrm{NH}_{3}}$ were affected by collection time in a quadratic way. Maximum concentrations of $\mathrm{N}_{-} \mathrm{NH}_{3}, 15.55,15.83,18.32,12.0 \mathrm{mg} / 100 \mathrm{~mL}$, were observed at 4:28, 3:58, 2:99 and 2:80h after feeding, for the diets including Tifton 85 hay with 5, 7, 10mm and whole particle sizes, respectively. It was concluded that all diets allowed normal nycterohemeral patterns of fermentation.

Key words: Ammonia nitrogen, fermentation, $\mathrm{PH}$, ruminants

\section{Introdução}

A digestão nos compartimentos gástricos e nos segmentos iniciais do intestino delgado tem a função de reduzir as formas poliméricas complexas em substâncias simples (monossacarídeos e aminoácidos) para serem assimilados ao longo do trato gastrintestinal. Os processos de digestão e fermentação executados pelos microrganismos ruminais fornecem os produtos finais da fermentação (ácidos graxos voláteis), que são utilizados como fonte de energia, e a massa microbiana, cuja constituição protéica representa uma fonte de aminoácidos para o hospedeiro.

O sistema CNCPS (Cornell Net Carbohydrate and Protein System) sugere a divisão do ecossistema ruminal em dois grupos microbianos, ou seja, os microrganismos que utilizam carboidratos estruturais, e aqueles que utilizam carboidratos não estruturais. Esta segregação reflete diferenças quanto às fontes de energia e compostos nitrogenados utilizados, bem como a eficiência do crescimento microbiano, pois as bactérias que fermentam carboidratos estruturais necessitam de amônia, que constitui sua principal fonte de $\mathrm{N}$ e ácidos graxos de cadeia ramificada. Por outro lado, não utilizam peptídeos e aminoácidos. Quando em condições limitantes de $\mathrm{N}$, apresentam menor crescimento, decorrentes dos maiores custos de mantença dos microrganismos. As bactérias que fermentam carboidratos não estruturais apresentam crescimento mais rápido e utilizam em média $66 \%$ de peptídeos e aminoácidos e 34\% de amônia para o seu crescimento (RUSSELL et al., 1992).

Os microrganismos ruminais dependem de esqueletos de carbono, de disponibilidade de energia e de um concomitante fornecimento de amônia e peptídeos para que haja síntese microbiana. A disponibilidade de carboidratos no rúmen é muito importante e tem grande efeito sobre a utilização dos compostos nitrogenados, pois as bactérias ruminais podem incorporar os aminoácidos e fermentá-los como fonte de energia. Por meio da manipulação da relação volumoso:concentrado é possível alterar os processos fermentativos e maximizar a eficiência de síntese microbiana, bem como a eficiência de utilização dos nutrientes dietéticos (RUSSELL et al., 1992).

Considerando que em condições tropicais, os carboidratos fibrosos são a maior fonte de energia no rúmen, a disponibilidade de $\mathrm{NH}_{3}$ é crucial nessas condições. A amônia gerada no rúmen é oriunda da fração $\mathrm{A}$, da degradação protéica da uréia reciclada no rúmen e da lise de células microbianas. O $\mathrm{N}$-amoniacal é removido do rúmen por diversos caminhos, tais como, a incorporação na matéria microbiana, que sai do rúmen, e a absorção por intermédio da parede ruminal e fluido, escoando para os próximos segmentos do trato digestório (FORBES; FRANCE, 1993). Nolan e Leng (1972) estimaram que de 60 a $90 \%$ do $\mathrm{N}$ dietético é convertido a $\mathrm{NH}_{3}$ no rúmen e, que de 50 a $80 \%$ do $\mathrm{N}$ microbiano é oriundo deste. $\mathrm{ANH}_{3}$, uma vez presente no rúmen, é assimilada pelos microrganismos a partir de duas rotas principais: a) por meio da enzima glutamato desidrogenase (GDH) e b) pelas enzimas glutamina sintetase e glutamato sintetase (GS-GOGAT). O sistema GDH, por apresentar baixa afinidade (alto $\mathrm{Km}$ ), prevalece em condições de elevadas concentrações de $\mathrm{NH}_{3}$, sem gasto de ATP; entretanto, o sistema GS-GOGAT, apresenta alta afinidade (baixo $\mathrm{Km}$ ) e atua efetivamente em 
baixas concentrações de $\mathrm{NH}_{3}$, portanto com gasto de ATP (ERFLE; SAUER; MAHADEVAN, 1977). Considerando que a produção de ATP nos ambientes anaeróbicos como o rúmen é relativamente baixo, as vias de assimilação de nutrientes exercem um grande efeito sobre a eficiência microbiana. Desta forma, a manutenção de concentrações adequadas de $\mathrm{NH}_{3}$ é fator crítico.

SattereSlyter(1974)sugeriramqueaconcentração mínima de $\mathrm{NH}_{3}$ para não limitar a digestão da fibra é de $50 \mathrm{mg} / \mathrm{L}$ de fluido ruminal. Entretanto, provavelmente, esta não é a concentração ótima, na qual o crescimento microbiano é maximizado, sem que ocorram significativas perdas por meio do epitélio ruminal.

Em condições normais, o $\mathrm{pH}$ ruminal é mantido em limites fisiológicos (6,6 a 7,2), condição esta desejável para ótima digestão da fibra. Entretanto, algumas condições dietéticas (alto amido, moagem, redução de tamanho de partículas), tendem a propiciar o acúmulo de íons $\mathrm{H}^{+}$e a redução do $\mathrm{pH}$ ruminal, que resulta em redução da síntese microbiana e da digestão da fibra. A redução do crescimento microbiano pode ser resultado do desacoplamento energético, por meio do consumo de gradiente de prótons transmembrana, ou pelo acúmulo de anions no interior da célula (RUSSELL et al., 1992).

Segundo Van Soest (1982), rações a base de concentrado apresentam pico de fermentação de duas a três horas após a ingestão, enquanto rações à base de forragem possuem o pico de fermentação de quatro a cinco horas após o fornecimento das mesmas. Os produtos ácidos originados da fermentação ruminal reduzem o $\mathrm{pH}$ do rúmen. Com rações ricas em concentrados, o $\mathrm{pH}$ do fluido ruminal apresenta-se normalmente entre 5,5 a 6,5, enquanto que em rações ricas em forragens, os valores esperados estão entre 6,2 a 7,0.

A efetividade física da fibra está relacionada, com as características físicas da fibra dietética que influenciam a atividade de mastigação e a natureza bifásica do conteúdo ruminal, sendo definidas e determinadas quantitativamente em laboratórios. As partículas que aparecem nas fezes escaparam do rúmen e podem ser usadas para indicar o tamanho das partículas que não necessitam ou não são capazes de estimular a mastigação(MERTENS, 1997). Há maior tempo de retenção ruminal de partículas quando o seu comprimento supera $1,18 \mathrm{~mm}$, sendo sugerido que a efetividade física pode ser determinada em laboratório, mediante o uso de peneiras com essa malha para separação da fração do alimento que apresenta efetividade (POPPI; HENDRICKSEN; MINSON, 1985; MERTENS, 1997). Entretanto, foram sugeridos comprimentos maiores (de 3 a $4 \mathrm{~mm}$ ) para novilhos (DIXON; MILLIGAN, 1985) e para vacas leiteiras (CARDOZA; MERTENS, 1986).

Desta forma, tem sido proposta a efetividade física como um parâmetro a ser utilizado na determinação da exigência de fibra pelo ruminante. Embora os conceitos estejam relacionados, a efetividade da fibra na percentagem de gordura do leite, é diferente da efetividade de fibra em estimular a atividade de mastigação.

Este trabalho teve como objetivo avaliar os efeitos de dietas com diferentes tamanhos de partículas de feno de Tifton 85 (Cynodon spp) sobre o $\mathrm{pH}$ e o nitrogênio amoniacal $\left(\mathrm{N}-\mathrm{NH}_{3}\right)$ ruminal em novilhos holandeses castrados.

\section{Material e Métodos}

O experimento foi realizado na Fazenda Antônio Carlos dos Santos Pessoa da Unioeste Campus de Marechal Cândido Rondon-PR. Foram utilizados quatro animais holandeses, pesando em média $300 \mathrm{~kg}$ de PV, fistulados no rúmen, alojados em baias individuais, dotadas de comedouros convencionais e bebedouros adaptados. Os animais foram distribuídos em quatro dietas experimentais à base de Feno de Tifton 85 com diferentes tamanhos de partículas $(5,7,10 \mathrm{~mm}$ e inteiro), em quatro períodos experimentais os quais tiveram duração 
de 16 dias cada, sendo 15 dias de adaptação à dieta. No último dia de cada período experimental foram realizadas as coletas de líquido ruminal. As rações foram formuladas de acordo com o NATIONAL RESEARCH COUNCIL - NRC (2001), para conterem em média 16\% de proteína bruta, adotando-se a relação volumoso:concentrado de 60:40, na base da matéria seca. A proporção dos ingredientes no concentrado e a composição químico-bromatológica dos alimentos e dieta estão apresentadas nas Tabelas 1 e 2 .

Tabela 1. Proporção dos ingredientes no concentrado, em base seca (\%MS), utilizado nos tratamentos com tamanhos de partículas de 5,7,10mm e inteiro na dieta

\begin{tabular}{lcc}
\hline & Ingredientes & Proporção (\%) \\
\hline Fubá de Milho & 60,00 \\
Farelo de Trigo & 16,00 \\
Farelo de Soja & 20,00 \\
Premix $^{1}$ & 4,00 \\
\hline
\end{tabular}

${ }^{1} 0,26 \%$ de Fosfato bicálcico, $0,62 \%$ de cloreto de sódio, $0,12 \%$ de sulfato de cobalto, $7,40 \%$ de sulfato de cobre, $0,24 \%$ de iodato de potássio, $31 \%$ de sulfato de zinco.

Tabela 2. Composição química em matéria seca (MS), matéria orgânica (MO), proteína bruta (PB), extrato etéreo (EE), matéria mineral (MM), carboidratos totais $(\mathrm{CT})$, carboidratos não estruturais (CNE), fibra em detergente neutro (FDN), fibra em detergente ácido (FDA) dos alimentos, do concentrado e das dietas experimentais

\begin{tabular}{lccccccccc}
\hline \multirow{2}{*}{ Itens } & \multicolumn{8}{c}{ Composição química (\% na MS) } \\
\cline { 2 - 9 } & MS & MO & PB & EE & MM & CT & FDN & CNE & FDA \\
\hline Feno de Tifton 85 & 91,76 & 91,59 & 14,36 & 1,96 & 8,36 & 75,32 & 79,18 & 3,86 & 40,02 \\
Fubá de Milho & 87,93 & 98,35 & 9,82 & 4,15 & 1,65 & 84,38 & 12,00 & 72,38 & 6,00 \\
Farelo de Trigo & 87,91 & 92,93 & 16,79 & 3,56 & 7,07 & 72,58 & 49,48 & 28,10 & 13,73 \\
Farelo de Soja & 88,56 & 93,06 & 45,68 & 1,63 & 6,26 & 55,53 & 14,81 & 40,72 & 9,56 \\
Concentrado & 88,85 & 94,67 & 17,27 & 3,93 & 5,54 & 73,26 & 17,18 & 56,08 & 6,29 \\
Dieta & 90,60 & 92,82 & 15,53 & 2,75 & 7,24 & 74,49 & 54,38 & 20,11 & 6,53 \\
\hline
\end{tabular}

Os animais foram pesados no início e no final de cada período experimental. A dieta total foi fornecida à vontade, duas vezes ao dia às $6: 30$ e às 13:30 horas.

As coletas de líquido ruminal, para determinação dopHedasconcentraçõesdeN-NH , foramrealizadas imediatamente antes do fornecimento da alimentação e 2; 4; 6; e 8 horas após a alimentação, no último dia de cada período experimental. Foram coletadas, por meio de fístula ruminal, aproximadamente $50 \mathrm{~mL}$ de líquido, procedendo-se a imediata determinação do $\mathrm{pH}$, em peagâmetro digital. Após a leitura do $\mathrm{pH}$, foi adicionado à cada amostra, $1 \mathrm{~mL}$ de solução de ácido sulfúrico $1: 1$, a qual foi armazenada $\mathrm{a}-5^{\circ} \mathrm{C}$, para posterior determinação das concentrações de nitrogênio amoniacal. As concentrações de $\mathrm{N}_{-} \mathrm{NH}_{3}$ nas amostras de líquido ruminal filtrado foram determinadas mediante destilação com hidróxido de potássio 2N, conforme técnicas de Fenner (1965), adaptadas por Vieira (1980).

Os alimentos foram analisados para matéria seca (MS), matéria mineral(MM), matéria orgânica (MO), proteína bruta $(\mathrm{PB})$ e extrato etéreo $(\mathrm{EE})$, seguindo os procedimentos padrões (ASSOCIATION OF 
OFFICIAL ANALYTICAL CHEMISTS - AOAC, 1990); e fibra em detergente neutro (FDN) e ácido (FDA), conforme técnica descrita por Van Soest, Robertson e Lewis (1991). Os carboidratos totais (CT) e carboidratos não estruturais (CNE) foram determinados conforme Sniffen et al. (1992).

O delineamento experimental foi o inteiramente casualizado, em esquema de parcelas subdivididas, tendo nas parcelas os tratamentos experimentais (feno inteiro, 5, 7 e 10mm) e nas sub-parcelas os tempos de coleta $(0,2,4,6,8 \mathrm{~h})$, com quatro repetições. Os dados obtidos foram avaliados por meio de análise de variância e regressão utilizando-se o programa SAEG - Sistemas de análises estatísticas e genéticas (UNIVERSIDADE FEDERAL DE VIÇOSA - UFV, 1997).

\section{Resultados e Discussão}

As equações de regressão ajustadas para as leituras de $\mathrm{pH}$ no líquido ruminal, em função do tempo após alimentação dos animais, para as rações experimentais de 7 e $10 \mathrm{~mm}$, estão expressas na Figura 1. A utilização de dietas constituídas de partículas com tamanhos de $5 \mathrm{~mm}$ e partículas inteiras não afetaram o $\mathrm{pH}$ ruminal $(\mathrm{P}>0,05)$, registrandose valores médios 6,14 e 6,61, respectivamente, cujos valores foram semelhantes aos observado por Bezerra (2000). O uso de dieta total, em geral, traz como vantagem a ausência de seleção pelo animal, sendo cada bocado uniforme, o que contribui para a manutenção de um padrão nictemeral de fermentação uniforme (COPPOCK, 1995; STOKES, 1997).

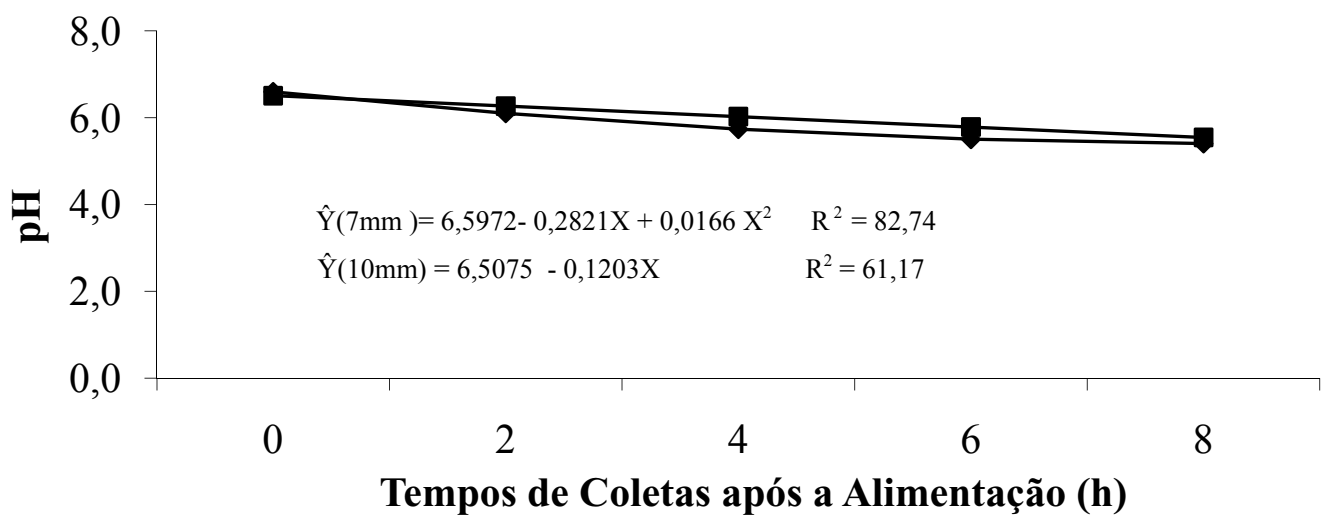

Figura 1. Estimativas dos valores de $\mathrm{pH}$ no líquido ruminal em função dos tempos de coleta, para as rações experimentais em novilhos.

Verificou-se redução linear no $\mathrm{pH}$ ruminal dos novilhos alimentados com dieta constituída de partícula de $10 \mathrm{~mm}$. Neste padrão dietético, provavelmente, ocorreu intensificação do processo de fermentação após a alimentação e conseqüente aumento nas concentrações de ácidos graxos voláteis, bem como aumento da produção de ácido láctico, promovendo desta forma, a queda do $\mathrm{pH}$ ruminal. Tais condições dietéticas têm como conseqüência, a redução do crescimento microbiano e da digestão da fibra, afetando com isso o consumo e o desempenho dos animais, mas em casos extremos, podem causar ruminite.

Observou-se efeito quadrático positivo para a variação de $\mathrm{pH}$ em função do tempo após alimentação na dieta constituída de tamanho de partícula de $7 \mathrm{~mm}$ de feno de Tifton, apresentando $\mathrm{pH}$ mínimo de 5,39 às 8,00 horas após o fornecimento da alimentação. Os valores médios de $\mathrm{pH}$ para todos os tratamentos estiveram próximos da faixa aceitável para o máximo crescimento microbiano e máxima digestão ruminal da fração fibrosa, que segundo, Silva e Leão (1979), 
Orskov(1988), Cecava et al.(1990)e Oliveira(1998), está entre 5,5 a 7,1. Assim, pode-se presumir que as dietas experimentais proporcionaram condições similares para a eficiência de síntese microbiana no ecossistema ruminal.

As equações de regressão ajustadas para as concentrações de nitrogênio amoniacal $\left(\mathrm{N}-\mathrm{NH}_{3}\right)$, no líquido ruminal, em função do tempo após alimentação, para os tratamentos experimentais, estão expressas na Figura 2. As concentrações de $\mathrm{N}-\mathrm{NH}_{3}$ foram influenciadas quadráticamente pelos tempos de coleta, registrando-se concentrações máximas, de 15,$55 ; 15,83 ; 18,32$ e $12,03 \mathrm{mgN}-$ $\mathrm{NH}_{3} / 100 \mathrm{~mL}$ às 4,28; 3,58; 2,99 e 2,80 horas após alimentação, respectivamente, paras as dietas constituídas de feno de Tifton 85 inteiro, picado em $5 \mathrm{~mm}, 7 \mathrm{~mm}$ e $10 \mathrm{~mm}$, respectivamente. Observouse que o pico máximo de concentração de $\mathrm{N}-\mathrm{NH}_{3}$, ocorreu entre 3,50 a 4,30 horas após o fornecimento das dietas para os tratamentos $5 \mathrm{~mm}$ e feno inteiro e próximo de 3,00 horas para os tratamentos com $7 \mathrm{~mm}$ e $10 \mathrm{~mm}$. Este comportamento está de acordo com as observações de Hennessy et al.(1995), que registraram em novilhos, maior concentração de amônia 3 horas após a alimentação.

As concentrações médias de nitrogênio amoniacal (Tabela 3), em todas as dietas $(10,34 \mathrm{mgN}-\mathrm{NH} 3)$ estiveram acima do mínimo requerido para o máximo crescimento microbiano e máxima taxa de digestão, que segundo Church (1988) é de 5,0 $\mathrm{mg} / 100 \mathrm{~mL}$.

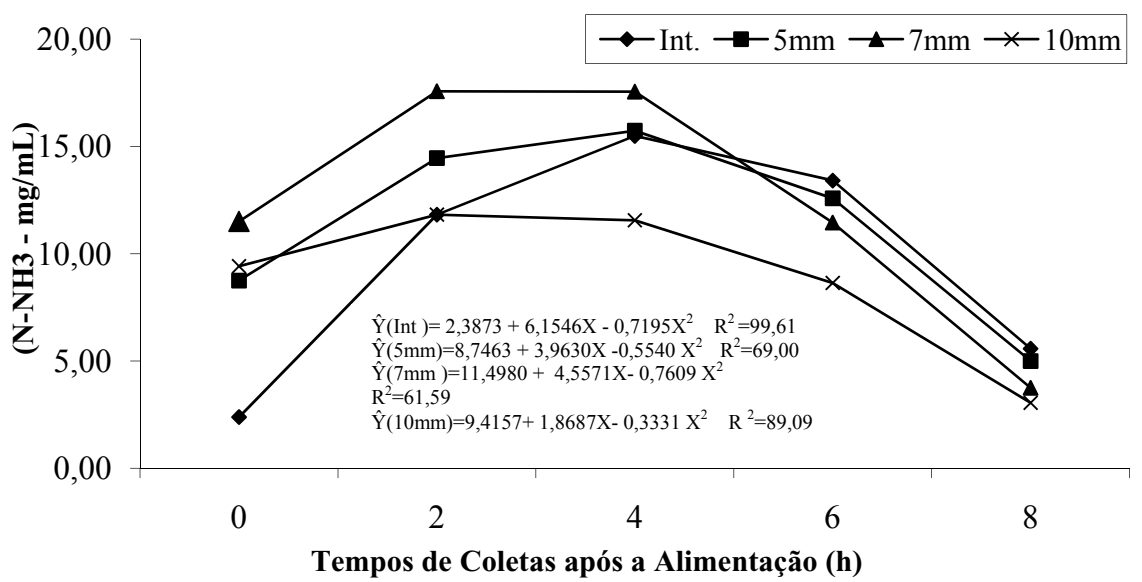

Figura 2. Estimativa das concentrações de nitrogênio amoniacal( $\left(\mathrm{N}^{-\mathrm{NH}_{3}}\right)$ no líquido ruminal, em função dos tempos de coleta, para as rações experimentais em novilhos.

Tabela 3. Concentrações médias de nitrogênio amoniacal $\left(\mathrm{N}^{\left.-\mathrm{NH}_{3}\right)}\right.$ no liquido ruminal, em função dos tempos de coleta, para as rações experimentais em novilhos

\begin{tabular}{lllll}
\hline \multirow{2}{*}{ Item } & \multicolumn{4}{c}{ Concentrações médias $\mathrm{N}^{-N_{3}}$ no liquido ruminal } \\
\cline { 2 - 5 } & \multicolumn{5}{c}{ Tratamento } \\
\cline { 2 - 5 } & Inteiro & $5 \mathrm{~mm}$ & $7 \mathrm{~mm}$ & $10 \mathrm{~mm}$ \\
\hline $\mathrm{N}^{-\mathrm{NH}_{3}}$ & 9,73 & 11,30 & 11,46 & 8,89 \\
\hline
\end{tabular}

$(\mathrm{P}>0,05)$. 
Estas concentrações de $\mathrm{NH}_{3}$ teoricamente são adequadas para atender as exigências em $\mathrm{N}$ dos microrganismos que fermentam carboidratos fibrosos, os quais predominam no rúmen. Além disso, o Sistema CNCPS, considera que as bactérias fermentadoras de carboidratos não estruturais utilizam $66 \%$ do $\mathrm{N}$ oriundo de peptídeos e aminoácidos e $34 \%$ de $\mathrm{N}-\mathrm{NH}_{3}$, porém bactérias do gênero Fibrobacter utilizam apenas amônia como fonte de crescimento. Neste sentido, Preston (1986), relatou que a taxa de desaparecimento de FDN é aumentada quando as concentrações de nitrogênio amoniacal elevam até um patamar de $20 \mathrm{mg} / 100 \mathrm{~mL}$ no líquido ruminal.

\section{Conclusão}

Dietas incluindo feno de Tifton 85 picados em partículas de $5,7,10 \mathrm{~mm}$ e inteiros permitiram padrões nictemerais normais de fermentação.

\section{Referências}

ASSOCIATION OF OFFICIAL ANALYTICAL CHEMISTS - AOAC. Official methods of analysis. 15.ed. Virginia: Arlington, 1990. v. 1.

BEZERRA, E. D. Efetividade fisica da fibra na dieta de vacas leiteiras. 2000. Tese. (Doutorado em Zootecnia) Universidade Federal de Viçosa, Viçosa.

CARDOZA, R. S.; MERTENS, D. R. Effect of fiber source and content on threeshold size for passage and fecal particle distribution. Journal of Dairy Science, Champaign, v. 69, Supple. 1, p. 134, 1986.

CECAVA, J. M.; MERCHEN, N. R.; GAY, L. C.; BERGER, L. L. Composition of ruminal bacteria harvested from steers as influenced by dietary energy level, feeding frequency, and isolation technique. Journal of Dairy Science, Champaign, v. 73, n. 9, p. 2480-2488, 1990.

CHURCH, D. C. The ruminant animal digestive physiology and nutrition. Engleewood Cliffs: O e B Books, 1988.

COPPOCK, C. E. Sistemas de alimentação e estratégias para o fornecimento de rações completas ("TMRS"). In: SIMPÓSIO INTERNACIONAL SOBRE PRODUÇÃO
INTENSIVA DE LEITE, 2., 1995, São Paulo. Anais... São Paulo: USP, 1995. p. 1-10.

DIXON, R. M.; MILLIGAN, L. P. Removal of digesta components from the rumen of steers determined by sieving techniques and fluid, particulate and microbial markers. British Journal of Nutrition, Cambridge, v. 53, n. 2, p. 347-362, 1985.

ERFLE, J. D.; SAUER, F. D.; MAHADEVAN, S. Effect of ammonia concentration on activity of enzymes of ammonia assimilation and on synthesis of amino acids by mixed rumen bacterial in continuous culture. Journal of Dairy Science, Champaign, v. 60, n. 7, p. 1064-1072, 1977.

FORBES, J. M.; FRANCE, J. Quantitative aspects of ruminant digestion and metabolism. Wallingford: $\mathrm{CAB}$ International, 1993.

HENNESSY, D. W.; KOHUN, P. J.; WILLIAMSON, P. J.; BROWN, D. A.; NOLAN, J. V. The effect of nitrogen and protein supplementation on feed intake, growth and digestive function of steers with different Bos indicus, Bos taurus genotypes when fed a low quality grass hay. Australian Journal of Agriculture Science, Collingwood, v. 46, n. 6, p. 1122-1136, 1995.

MERTENS, D. R. Creating a system for meeting the fiber requirements of dairy cows. Journal of Dairy Science, Champaign, v. 80, n. 7, p. 1463-1481, 1997.

NATIONAL RESEARCH COUNCIL - NRC. Nutrient requirements of dairy cattle. 7.ed. Washington: National Academy Press, 2001.

NOLAN, J. V.; LENG, R. A. Dynamic aspects of ammonia and urea metabolism in sheep. British Journal of Nutrition, Cambridge, v.27, n. 1, p.177-194, 1972.

OLIVEIRA, R. L. Cinética digestiva em novilhos submetidos a dietas com diferentes niveis de cama de frango e de suplemento á base de microbiota ruminal. Viçosa: Ed. da UFV, 1998.

ORSKOV, E. R. Nutrición proteica de los rumiantes. Zaragoza: Acribia, 1988.

POPPI, D. P.; HENDRICKSEN, R. E.; MINSON, D. J. The relative resistance to escape of leaf and steam particle from the rumen of cattle and sheep. Journal of Agriculture Science, Cambridge, v. 105, n. 1, p. 9, 1985.

PRESTON, T. R. Better utilization of crop residues and by-products in animal feeding: research guigelines. 2 . A practical manual for research workers. Rome: FAO, 1986.

RUSSELL, J. B.; O'CONNOR, J. D.; FOX, D. G.; VAN SOEST, P. J.; SNIFFEN, C. J. A net carbohydrate and 
protein system for evaluating cattle diets: I. Ruminal fermentation. Journal of Animal Science, Champaign, v. 70, n. 11, p. 3551-3561, 1992.

SATTER, L. D.; SLYTER, L. L. Effect of ammonia concentration on rumen microbial production in vitro. Brithish Journal of Nutrition, Cambridge, v. 32, n. 2, p. 199-208, 1974.

SILVA, J. F. C.; LEÃO, M. I. Fundamentos de nutrição de ruminantes. Piracicaba: Livroceres, 1979.

SNIFFEN, C. J.; O'CONNOR, J. D.; VAN SOEST, P. J.; FOX, D. G.; RUSSELL, J. B. A net carbohydrate and protein system for evaluating cattle diets. II - Carbohydrate and protein availability. Journal of Animal Science, Champaign, v. 70, n. 11, p. 3562-3577, 1992.

STOKES, S. R. Particle size and ration uniformity: is it important to the cow? In: WESTERN CANADIAN DAIRY SEMINAR, 15., 1997, Alberta. Proceedings... Stephenville: Texas A\&M University, 1997. p. 1-10.
UNIVERSIDADE FEDERAL DE VIÇOSA - UFV. Sistema de análises estatísticas e genética - SAEG. Viçosa: Ed. da UFV, 1997.

VAN SOEST, P. J. Nutricional ecology of the ruminants. Corvallis: O e B Books, 1982.

VAN SOEST, P. J; ROBERTSON, J. B.; LEWIS, B. A. Methods for dietary fiber, neutral detergent fiber, and nonstarch polysaccharides in relation to animal nutrition. Journal of Dairy Science, Champaign, v. 74, n. 10, p. 35833597, 1991.

VIEIRA, P. F. Efeito do formaldeído na proteção de proteinas e lipídeos em rações para ruminantes. 1980. Tese. (Doutorado em Zootecnia) - Universidade Federal de Viçosa, Viçosa. 